\title{
Physiological Response to Feeding in Little Penguins
}

\section{J. A. Green ${ }^{1,2, \star}$ \\ P. B. Frappell ${ }^{1}$ \\ T. D. Clark ${ }^{1, \dagger}$ \\ P. J. Butler ${ }^{2}$}

${ }^{1}$ Adaptive and Evolutionary Respiratory Physiology Laboratory, Department of Zoology, La Trobe University, Melbourne, Victoria 3086, Australia; ${ }^{2}$ Centre for Ornithology, School of Biosciences, University of Birmingham, Edgbaston, Birmingham B15 2TT, United Kingdom

Accepted 6/30/2006; Electronically Published 10/2/2006

\begin{abstract}
Specific dynamic action (SDA), the increase in metabolic rate above resting levels that accompanies the processes of digestion and assimilation of food, can form a substantial part of the daily energy budget of free-ranging animals. We measured heart rate $\left(f_{\mathrm{H}}\right)$ and rate of oxygen consumption $\left(\dot{\mathrm{V}}_{2}\right)$ in 12 little penguins while they digested a meal of sardines in order to determine whether they show specific dynamic action. In contrast to some studies of other penguin species, little penguins showed a substantial SDA, the magnitude of which was proportional to the size of the meal. The energy utilized in SDA was equivalent to $13.4 \%$ of the available energy content of the fish. Furthermore, animals such as penguins that forage in a cold environment will probably expend further energy in heating their food to body temperature to facilitate efficient digestion. It is estimated that this additional energy expenditure was equivalent to $1.6 \%-2.3 \%$ of the available energy content of the fish, depending on the time of year and therefore the temperature of the water. Changes in $f_{\mathrm{H}}$ during digestion were qualitatively similar to those in $\dot{\mathrm{V}}_{2}$, implying that there were no substantial circulatory adjustments during digestion and that the relationship between $f_{\mathrm{H}}$ and $\dot{\mathrm{V}}_{2}$ in penguins is unaffected by digestive state.
\end{abstract}

\footnotetext{
* Corresponding author; e-mail: jon.green@latrobe.edu.au.

${ }^{\dagger}$ Present address: School of Earth and Environmental Sciences, University of Adelaide, Adelaide, South Australia 5005, Australia.

Physiological and Biochemical Zoology 79(6):1088-1097. 2006. (C) 2006 by The University of Chicago. All rights reserved. 1522-2152/2006/7906$6031 \$ 15.00$
}

\section{Introduction}

The increase in metabolic rate (MR) above resting levels that accompanies the processes of digestion and assimilation of food by animals is commonly referred to as specific dynamic action (SDA; Rubner 1902). SDA is the sum of all of the mechanical and biochemical processes associated with digestion, absorption, and assimilation, and its magnitude will vary to some extent on the composition of the food (Blaxter 1989). For example, substrates with a high protein content tend to invoke a higher SDA because of the high costs of both protein catabolism and amino acid anabolism (Janes and Chappell 1995; Rosen and Trites 2003). Ultimately, though, the functional significance and the exact nature of SDA are still unclear (Blaxter 1989). What is accepted, however, is that the energy utilized in SDA can be as much as $40 \%-50 \%$ of the metabolizable energy of ingested food (MacArthur and Campbell 1994; Jensen et al. 1999) and, as a result, represents a substantial proportion of the energy budget of free-ranging animals.

Although SDA has been measured and quantified in several taxonomic groups, knowledge of this phenomenon among birds and mammals is both patchy and contradictory. For example, some studies have shown that the magnitude of SDA is a constant proportion of meal size (Janes and Chappell 1995), while others have shown that in smaller (Campbell et al. 2000) or less energy-dense (Markussen et al. 1994) meals, a greater proportion of the metabolizable energy is utilized in SDA. This could have significant implications on food choice and foraging ecology. Even within animals showing a proportional increase in SDA with meal size, this increase can manifest itself as simply an increase in the duration of digestion (Bech and Praesteng 2004) or an increase in both the duration and peak MR (Gallivan and Ronald 1981). In some studies, the increase in MR occurs immediately after ingestion (Hawkins et al. 1997), while in others, it is delayed (Costa and Kooyman 1984). The occurrence or magnitude of the SDA response may vary diurnally and, in small animals, may effectively occur at all times (Schieltz and Murphy 1997). In these animals, SDA could be considered a component of basal metabolism whether exogenous or endogenous reserves are being consumed (Schieltz and Murphy 1997). With the exception of studies on humans (e.g., Sidery and Macdonald 1994), the response of heart rate $\left(f_{\mathrm{H}}\right)$ to digestion has received scant attention among endotherms. The only attempted study thus far reported no change in $f_{\mathrm{H}}$ to accompany large changes in MR during digestion (McPhee et al. 2003).

Several studies have found that the excess heat generated by SDA can be substituted for thermoregulatory costs in thermally 
challenged animals (Bech and Praesteng 2004), while others have shown no such substitution (Kaseloo and Lovvorn 2003) even in species that spend the greater part of their life in cold environments (Rosen and Trites 2003). As well as the costs associated with SDA, aquatic predators feeding on ectothermic prey in a cold environment will bear an additional cost in heating their food from water temperature to normal body temperature in order for efficient digestion to occur (Wilson and Culik 1991). The magnitude of this cost will depend on the composition of the food and the difference between water temperature and body temperature.

The conflicting findings surrounding SDA in birds are exemplified by studies of the Adélie penguin (Pygoscelis adeliae). The two studies completed thus far have demonstrated both the presence (Janes and Chappell 1995) and absence (Wilson and Culik 1991) of SDA in this species. In this study, we evaluated the effects of digesting meals of different sizes on both the rate of oxygen consumption $\left(\dot{\mathrm{V}}_{2}\right.$, a proxy for $\left.\mathrm{MR}\right)$ and $f_{\mathrm{H}}$ of the little penguin (Eudyptula minor). This species feeds on protein-rich fish (Chiaradia et al. 2003) in cool temperate waters (Williams 1995), and the vulnerability of its populations to variability in its preferred food type has recently received much attention (Dann et al. 2000). Only by understanding all of the components of its annual energy budget can we hope to predict how this species might respond to environmental change. With this in mind, we set out to answer five specific questions. (1) Does SDA occur in this species? (2) If so, what proportion of the penguin's energy budget does it represent? (3) How does heart rate change during the time course of digestion in a bird? (4) What are the costs of heating food to body temperature? (5) How might this vary as animals forage in an environment where sea temperature varies throughout the year?

\section{Material and Methods}

Animals

Twelve wild-caught little penguins in six breeding pairs were obtained from Phillip Island Nature Park, Victoria, Australia (mean mass $\pm \mathrm{SEM}=1.07 \pm 0.02 \mathrm{~kg}$ ). Penguins were transported by car to La Trobe University, Melbourne, Australia, where all experiments took place. The experiments were performed between September 9 and September 21, 2004, which was during the prebreeding/courtship phase in this year ( $P$. Dann, personal communication). The penguins were kept in a large sand-based outside enclosure $(7.5 \mathrm{~m} \times 5 \mathrm{~m})$ that was half covered to provide protection from sun and rain. They were provided with artificial nesting burrows and a large rectangular swimming tank $(2 \mathrm{~m} \times 1.5 \mathrm{~m})$ filled with fresh water. The penguins were hand-fed 150-200 g of West Australian sardines (Sardinops neopilchardus) twice daily, supplemented daily with a multivitamin tablet. The penguins spent $6 \mathrm{~d}$ at La Trobe; during this time, they continued to cohabit with their breeding partner, and each penguin increased in body mass by an average of approximately $5 \%$.

\section{Apparatus}

Rates of oxygen consumption $\left(\dot{\mathrm{V}}_{2}\right)$ and carbon dioxide production $\left(\dot{\mathrm{V}}_{\mathrm{CO}_{2}}\right)$ were measured using an open-circuit respirometry system. A $45 \times 45 \times 55$-cm Perspex respirometer was housed within a constant temperature room set at $22.6^{\circ} \pm$ $0.1^{\circ} \mathrm{C}( \pm \mathrm{SEM})$, which is within the reported thermoneutral zone for this species (Stahel and Nicol 1982; Baudinette et al. 1986; Green et al. 2006). Air was drawn from the respirometer using a vacuum compressor at approximately $16-17 \mathrm{~L} \mathrm{~min}^{-1}$. Flow rate was monitored using an electronic mass-flow meter (Sierra Instruments). A subsample of air was drawn from this main flow using a small air pump (AMETEK R-1, Applied Electrochemistry), passed through a drying column (Drierite, Hammond), and analyzed for the fractional content of oxygen and carbon dioxide by two gas analyzers (AMETEK S-3A/I and AMETEK CD-3A). Heart rate was monitored using a customized heart rate transmitter system (POLAR a3, Polar Electro Oy, Finland). The heart rate transmitter was attached dorsally to the feathers using lightweight paper tape, and custom-made brass electrodes were inserted under the skin. The transmitter unit had a functional range of approximately $1 \mathrm{~m}$, and the receiver unit was placed on top of the respirometer to ensure a strong signal. Outputs from the heart rate receiver, gas analyzers, flow meter, and a thermocouple located inside the respirometer were collected at $200 \mathrm{~Hz}$ using a Powerlab system (Powerlab 8SP, ADInstruments, Australia) and displayed on a computer using Chart software (ADInstruments, Australia). Both $\dot{\mathrm{V}}_{2}$ and $\dot{\mathrm{V}}_{\mathrm{CO}_{2}}$ were determined from the rate of airflow from the respirometer and the difference in the fractional oxygen or carbon dioxide concentration between ambient and outflowing air. Instantaneous corrections of the gas concentrations were calculated dry at standard temperature $(273 \mathrm{~K})$ and pressure $(101.3 \mathrm{kPa})$ using the method of Frappell et al. (1989), assuming a first-order linear system (chamber volume $=101 \mathrm{~L}$; flow $=17 \mathrm{~L} \mathrm{~min} \operatorname{mon}^{-1} \tau=4.71 \mathrm{~min}$, determined from a semilogarithmic plot of concentration against time following a perturbation, $\left.r^{2}=0.99\right)$. $\dot{\mathrm{V}}_{2}$ was calculated with consideration of RQ-related errors (Frappell et al. 1992). Whole-system accuracy was determined to be $6 \%$ by bleeding $\mathrm{CO}_{2}$ into the respirometer at a known flow rate and backcalculating this rate. Rate of carbon dioxide production was used only to calculate the respiratory exchange ratio $(\mathrm{RER}=$ $\left.\dot{\mathrm{V}_{\mathrm{CO}}} / / \dot{\mathrm{V}}_{2}\right)$ for each minute of the experiment.

\section{Protocol}

In most studies of SDA, resting values of $\dot{\mathrm{V}}_{2}$ are obtained immediately before experimental feeding. In this study, this was not possible because the birds were hand-fed (see below). 
Therefore, resting $\dot{\mathrm{V}}_{2}$ and $f_{\mathrm{H}}$ were determined from data collected on another occasion, using the same birds and same apparatus. In these experiments, $\dot{\mathrm{V}}_{2}$ and $f_{\mathrm{H}}$ were calculated each minute while the birds were inactive for several hours (not exercising yet free to preen or move). In order to obtain $f_{\mathrm{H}}$ and $\dot{\mathrm{V}}_{2}$ in a stable state of rest, the following procedure was adopted. First, the data for both $\dot{\mathrm{V}}_{2}$ and $f_{\mathrm{H}}$ were ranked in ascending order. Second, mean and standard deviation (SD) of both $\dot{\mathrm{V}}_{2}$ and $f_{\mathrm{H}}$ were calculated for increasing sample sizes $(n)$ from 0 to 40 , starting with the lowest values of $\dot{\mathrm{V}}_{\mathrm{O}_{2}}$ and $f_{\mathrm{H}}$. Mean and SD were then both plotted as a function of $n$, and a plateau was observed in both at $n=15$. These mean values were used in all analyses because they typified a stable, repeatable state of rest (Tables 1,2).

Feeding trials were conducted $21-30 \mathrm{~h}$ after the penguin's last meal, and it was therefore assumed that animals were postabsorptive. The penguins were hand-fed outside the respirometer because this was the only way that they would feed under short-term captive conditions. The birds had been hand-fed twice-daily in the holding aviary and were accustomed to handfeeding; thus, feeding took less than $1 \mathrm{~min}$ in either case. In order to separate the potential stress effects of feeding and handling the penguins, each penguin was used for both a feeding trial and a control trial. During both feeding and control trials, the penguins were removed from their carrying box and handled while the heart rate transmitter was attached to the back. During control trials, the birds were then immediately placed into the respirometer, while during feeding trials, the penguins were fed either a small meal (two sardines, mean mass $\pm \mathrm{SEM}=30.5 \pm 1.0 \mathrm{~g}$ ) or a large meal (five sardines, mean mass $=74.9 \pm 1.3 \mathrm{~g}$. The large meal was 2.45 times larger than the small meal, and the masses of the meals were equivalent to $2.8 \% \pm 0.16 \%$ and $7.1 \% \pm 0.27 \%$, respectively, of the body mass of the penguins. The sardines were stored in a refrigerator at $7^{\circ} \mathrm{C}$ and fed to the penguins immediately on removal. After feeding, as during control trials, the penguins were placed immediately in the respirometer. During both trials, the penguins remained in the respirometer until $f_{\mathrm{H}}$ and $\dot{\mathrm{V}}_{2}$ appeared to return to the resting values observed previously for that individual. Each penguin was used in a single feeding and control trial, with its allocation to the small meal or large meal group determined randomly.

\section{Analysis}

Data were initially processed using Chart software, and further analyses used Excel (Microsoft) and Minitab (Minitab). Rate of oxygen consumption and $f_{\mathrm{H}}$ were calculated for each minute for the duration of each trial. An assumption was made that SDA (defined here as the additional volume of oxygen consumed during digestion above resting $\dot{\mathrm{V}}_{2}$ ) and handling stress effects were additive, as in a previous study of Adélie penguin chicks (Janes and Chappell 1995). Therefore, for each animal, both "feeding costs" and "handling costs" (i.e., the amount of oxygen consumed as a result of either feeding or handling) were calculated, and handling costs were subtracted from feeding costs to determine SDA. Both feeding costs and handling costs were calculated using the same procedure. The time series of data was initially visually inspected, and data were removed from the start of the file, which corresponded to adjustment to new surroundings and the lag associated with the respirometry system. After this initial phase $(\sim 10 \mathrm{~min})$, the penguins settled and rested quietly in the respirometer. In each case, $\dot{\mathrm{V}}_{2}$ and $f_{\mathrm{H}}$ were elevated above resting levels, which was presumed to represent the response to either handling or both handling and feeding. Both $f_{\mathrm{H}}$ and $\dot{\mathrm{V}}_{2}$ showed a steady linear decline over the succeeding few hours (Fig. 1).

Preliminary data analysis quickly revealed that not all penguins attained their resting $\dot{\mathrm{V}}_{2}$ or $f_{\mathrm{H}}$ during the time course of the feeding trials. Therefore, a linear relationship between time and $\dot{\mathrm{V}}_{2}$ or $f_{\mathrm{H}}$ was calculated, and this line was extrapolated backward to obtain initial $\dot{\mathrm{V}}_{2}$ and $f_{\mathrm{H}}$ and forward to obtain the duration of the elevation in $\dot{\mathrm{V}}_{2}$ and $f_{\mathrm{H}}$. Since the decline in $\dot{\mathrm{V}}_{2}$ was linear, feeding or handling costs (in $\mathrm{mL} \mathrm{O}_{2}$ ) were calculated as the area under the curve above resting values for the duration of digestion or handling. SDA was then calculated as the increase in volume of $\mathrm{O}_{2}$ consumed above resting levels due to feeding, minus the increase in volume of $\mathrm{O}_{2}$ consumed above resting levels due to handling. The increases in $f_{\mathrm{H}}$ associated with handling or handling and digestion together were

Table 1: Effect of meal ingestion on the rate of oxygen consumption $\left(\dot{\mathrm{V}}_{2}\right)$ in little penguins

\begin{tabular}{|c|c|c|c|c|c|c|c|c|}
\hline Meal Size & $n$ & $\begin{array}{l}\text { Meal Mass } \\
(\mathrm{g})\end{array}$ & $\begin{array}{l}\text { Resting } \dot{\mathrm{V}}_{\mathrm{O}_{2}} \\
\left(\mathrm{~mL} \min ^{-1}\right)\end{array}$ & $\begin{array}{l}\text { Initial } \dot{\mathrm{V}}_{\mathrm{O}_{2}} \\
\left(\mathrm{~mL} \min ^{-1}\right)\end{array}$ & $\begin{array}{l}\text { Peak } \dot{\mathrm{V}}_{\mathrm{O}_{2}} \\
\left(\mathrm{~mL} \min ^{-1}\right)\end{array}$ & $\begin{array}{l}\text { Duration of } \\
\text { Digestion (min) }\end{array}$ & $\begin{array}{l}\text { Specific Dynamic } \\
\text { Action }\left(\mathrm{mL} \mathrm{O}_{2}\right)\end{array}$ & $\begin{array}{l}\text { Mean } \dot{\mathrm{V}}_{2} \text { of Digestion } \\
\left(\mathrm{mL} \min ^{-1}\right)\end{array}$ \\
\hline Small & 6 & $30.5 \pm 1.0$ & $15.3 \pm 1.3$ & $20.4 \pm 1.5$ & $24.0 \pm .8$ & $185 \pm 19^{\mathrm{a}}$ & $937 \pm 161^{\mathrm{a}}$ & $5.0 \pm .5$ \\
\hline Large & 6 & $74.9 \pm 1.3$ & $15.0 \pm .8$ & $22.7 \pm 2.0$ & $28.0 \pm 1.6$ & $380 \pm 34^{\mathrm{a}}$ & $2,609 \pm 363^{\mathrm{a}}$ & $6.9 \pm .8$ \\
\hline Factorial increase & & 2.45 & .98 & 1.11 & 1.17 & 2.05 & 2.78 & 1.39 \\
\hline
\end{tabular}

Note. Values are means \pm SEM. Factorial increase is the value for the large meal divided by the value for the small meal. Initial $\dot{V}_{\mathrm{O}_{2}}$ is the first measurement following feeding, after subtraction of handling effects. Mean $\dot{\mathrm{V}}_{2}$ of digestion is the average $\dot{\mathrm{V}}_{2}$ above resting levels for the duration of the digestion, as defined for $\dot{\mathrm{V}}_{2}$.

${ }^{a}$ Indicates significant differences in quantities between meal sizes. 
Table 2: Effect of meal ingestion on the heart rate $\left(f_{\mathrm{H}}\right)$ in little penguins

\begin{tabular}{|c|c|c|c|c|c|c|c|c|}
\hline & $n$ & $\begin{array}{l}\text { Meal Mass } \\
(\mathrm{g})\end{array}$ & $\begin{array}{l}\text { Resting } f_{\mathrm{H}} \\
\left(\text { beats } \mathrm{min}^{-1} \text { ) }\right.\end{array}$ & $\begin{array}{l}\text { Initial } f_{\mathrm{H}} \\
\left(\text { beats } \min ^{-1} \text { ) }\right.\end{array}$ & $\begin{array}{l}\text { Peak } f_{\mathrm{H}} \\
\text { (beats } \min ^{-1} \text { ) }\end{array}$ & $\begin{array}{l}\text { Duration of } \\
\text { Digestion } \\
(\mathrm{min})\end{array}$ & $\begin{array}{l}\text { Heartbeats during } \\
\text { Digestion (beats) }\end{array}$ & $\begin{array}{l}\text { Mean } f_{\mathrm{H}} \text { of } \\
\text { Digestion } \\
\text { (beats) }\end{array}$ \\
\hline Small & 6 & $30.5 \pm 1.0$ & $117 \pm 3$ & $132 \pm 9$ & $149 \pm 5^{\mathrm{a}}$ & $207 \pm 22^{\mathrm{a}}$ & $3,275 \pm 682^{\mathrm{a}}$ & $16 \pm 3$ \\
\hline Large & 6 & $74.9 \pm 1.3$ & $129 \pm 7$ & $136 \pm 11$ & $182 \pm 2^{a}$ & $296 \pm 26^{a}$ & $7,975 \pm 1,182^{\mathrm{a}}$ & $28 \pm 4$ \\
\hline Factorial increase & & 2.45 & 1.11 & 1.03 & 1.22 & 1.43 & 2.44 & 1.73 \\
\hline
\end{tabular}

Note. Values are means \pm SEM. Factorial increase is the value for the large meal divided by the value for the small meal. Initial $f_{\mathrm{H}}$ is the first measurement following feeding, after subtraction of handling effects. Mean $f_{\mathrm{H}}$ of digestion is the average $f_{\mathrm{H}}$ above resting levels for the duration of the digestion, as defined for $f_{\mathrm{H}}$.

${ }^{a}$ Indicates significant differences in quantities between meal sizes.

calculated in an identical fashion. Digesting heartbeats (DHB; defined here as the additional number of heartbeats during digestion above resting $f_{\mathrm{H}}$ ) were given as the increase in the number of heartbeats above resting levels due to feeding minus the increase in the number of heartbeats above resting due to handling. Mean data are described \pm SEM unless otherwise stated. Statistical analysis utilized Student's $t$-test (paired where appropriate), and results were considered significant at $P<$ 0.05 .

\section{Results}

\section{Handling Effects}

After being placed in the respirometer during control trials, initial $\dot{\mathrm{V}}_{2}$ was $21.8 \pm 1.1 \mathrm{~mL} \mathrm{~min}{ }^{-1}$, which was $1.46 \pm 0.08$ times greater than resting $\dot{\mathrm{V}}_{2}$. The mean time for $\dot{\mathrm{V}}_{2}$ to return to resting levels was $43 \pm 4 \mathrm{~min}$, and the mean $\dot{\mathrm{V}}_{2}$ for the entire recovery period was $18.5 \pm 0.7 \mathrm{~mL} \mathrm{~min}^{-1}$, representing a mean increase above resting levels of $23 \% \pm 4 \%$. Similarly, initial $f_{\mathrm{H}}$ was $176 \pm 7$ beats $\min ^{-1}$, which was $1.44 \pm 0.05$ times greater than resting $f_{\mathrm{H}}$. The mean time for $f_{\mathrm{H}}$ to return to resting levels was $56 \pm 5 \mathrm{~min}$, and the mean $f_{\mathrm{H}}$ for the entire recovery period was $149 \pm 5$ beats $\min ^{-1}$, which represented a mean increase above resting levels of $23 \% \pm 2 \%$. The recovery period for $f_{\mathrm{H}}$ was significantly longer than that for $\dot{\mathrm{V}}_{2}$ (paired $t$-test, $\left.t_{11}=2.90, P<0.05\right)$.

\section{Rate of Oxygen Consumption during Digestion}

Subtraction of handling costs from feeding costs resulted in a pattern of change of $\dot{\mathrm{V}}_{2}$ during digestion characterized by an initial elevation above resting levels. The subtraction of handling costs is assumed to be complete, and therefore this initial elevated level of $\dot{\mathrm{V}}_{2}$ is assumed to be an immediate response to an ingestion of cold food and the commencement of heating and digestion. $\dot{\mathrm{V}}_{2}$ increased from this initial level to a peak that coincided with the end of handling costs. $\dot{\mathrm{V}}_{2}$ then proceeded to decline steadily to resting levels. Table 1 summarizes the variables measured during digestion and associated calculation of SDA. There was no significant difference between the large and small meal group in either initial $\dot{\mathrm{V}}_{\mathrm{O}_{2}}\left(t\right.$-test, $t_{9}=$
$0.94, P=0.37)$ or peak $\dot{\mathrm{V}}_{2}\left(t\right.$-test, $\left.t_{7}=2.28, P=0.26\right)$ during digestion. The duration of digestion was significantly longer in the large meal group ( $t$-test, $t_{8}=4.95, P<0.001$ ) as, therefore, was SDA ( $t$-test, $t_{7}=4.21, P<0.01$ ). Figure 2 shows several of these quantities put together and illustrates how SDA was 2.78 times larger for the large meal than for the small meal, which closely matches the relative difference in the size of the meals. In order to determine whether SDA was proportional to meal size, SDA was divided by meal mass $\left(\mathrm{SDA}_{\mathrm{m}}\right)$. There was no significant difference in $\mathrm{SDA}_{\mathrm{m}}$ between the large and small meal groups ( $t$-test, $t_{10}=0.60, P=0.56$ ). This indicates that $\mathrm{SDA}_{\mathrm{m}}$ was independent of meal size; thus, the pooled value of $\mathrm{SDA}_{\mathrm{m}}$ from all 12 trials of $33.0 \pm 3.6 \mathrm{~mL} \mathrm{O}_{2}(\mathrm{~g} \text { fish })^{-1}$ can be used in further analyses.

\section{Heart Rate during Digestion}

During digestion, $f_{\mathrm{H}}$ showed changes that were very similar to those observed in $\dot{\mathrm{V}}_{2}$. There was a much smaller initial response in $f_{\mathrm{H}}$, but after this, $f_{\mathrm{H}}$ increased to a peak that coincided with the end of handling costs and then decreased steadily toward resting levels. Table 2 summarizes the variables associated with $f_{\mathrm{H}}$ measured during digestion and the subsequent calculation of DHB. There was no significant difference in initial $f_{\mathrm{H}}$ between the large meal group and small meal group $(t-$ test, $t_{10}=1.46, P=0.18$ ). However, peak $f_{\mathrm{H}}$ was significantly greater in the large meal group than in the small meal group ( $t$-test, $\left.t_{6}=5.79, P<0.001\right)$. DHB was significantly greater in the large meal group than in the small group ( $t$-test, $t_{8}=$ $3.44, P<0.01$ ), as was the duration of digestion ( $t$-test, $t_{10}=$ $2.60, P<0.05)$. Figure 2 shows several of these quantities combined and illustrates how the magnitude of the response in $f_{\mathrm{H}}$ to digestion was increased for larger meals but to a lesser degree than the response of $\dot{\mathrm{V}}_{2}$. In the case of $f_{\mathrm{H}}$, DHB was 2.44 times greater for the large meal group than for the small meal group. When $\mathrm{DHB}$ was divided by meal size $\left(\mathrm{DHB}_{\mathrm{m}}\right)$, there was no significant difference between groups in $\mathrm{DHB}_{\mathrm{m}}$ ( $t$-test, $t_{9}=$ $0.01, P=0.99)$. This means that $\mathrm{DHB}$ is also proportional to meal size, and $\mathrm{DHB}_{\mathrm{m}}$ was independent of meal size. The pooled value for $\mathrm{DHB}_{\mathrm{m}}$ from all 12 trials of $107 \pm 13$ beats $(\mathrm{g} \text { fish })^{-1}$ was used in further analysis and interpretation. 

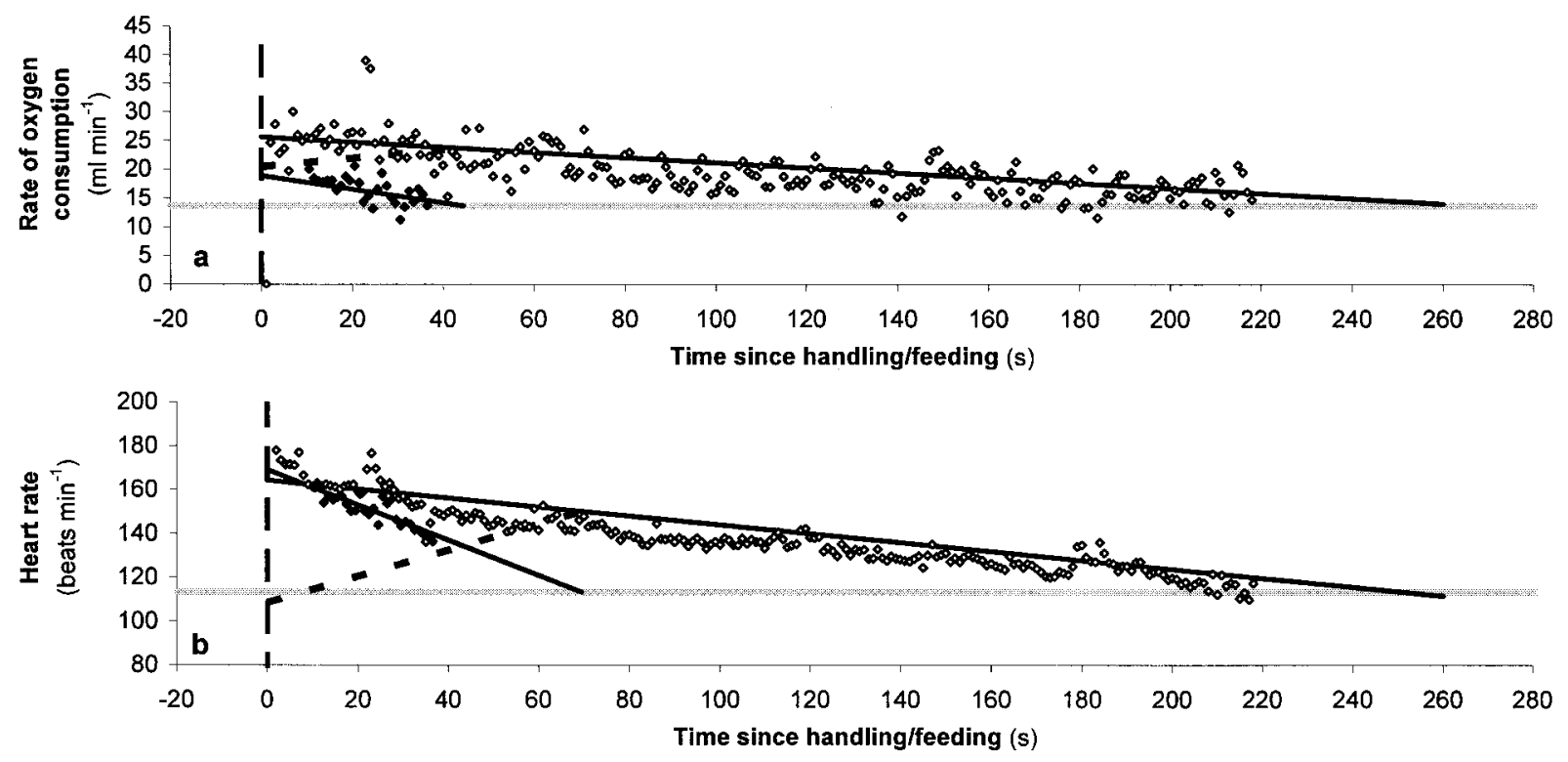

Figure 1. Decline in rate of oxygen consumption $\left(\dot{\mathrm{V}}_{2} ; a\right)$ and heart rate $\left(f_{\mathrm{H}} ; b\right)$ following the ingestion of a meal of two sardines $($ mass $=$ $31 \mathrm{~g}$; open symbols) or during a control trial (solid symbols). Data were recorded from a representative male little penguin $(\mathrm{mass}=1,070 \mathrm{~g})$. In each case, the solid lines represent the regression lines between time since handling or feeding and $\dot{V}_{\mathrm{O}_{2}}$ or $f_{\mathrm{H}}$. These lines were extrapolated backward to time 0 (dashed vertical line) to obtain initial $\dot{\mathrm{V}}_{2}$ and $f_{\mathrm{H}}$ and forward to the intersection with the gray lines (representing resting $\dot{\mathrm{V}}_{\mathrm{O}_{2}}$ and $f_{\mathrm{H}}$ for that individual) to obtain the duration of the elevation in $\dot{\mathrm{V}}_{2}$ and $f_{\mathrm{H}}$ (duration of digestion). Specific dynamic action was calculated by subtracting handling effects from digestion/feeding effects. The resultant rate of oxygen consumption during digestion excluding handling effects is indicated by the dotted line.

\section{Interaction between Heart Rate and Rate of Oxygen Consumption}

Heart rate and $\dot{\mathrm{V}}_{2}$ displayed similar patterns during the entire digestive period, with one notable exception. Duration of digestion was calculated as the time taken for either $\dot{\mathrm{V}}_{\mathrm{O}_{2}}$ or $f_{\mathrm{H}}$ to return to resting levels. In the small meal group, there was no difference in the duration of digestion, whether it was calculated using $f_{\mathrm{H}}$ or $\dot{\mathrm{V}}_{2}$ (paired $t$-test, $t_{5}=1.34, P=0.24$ ). However, in the large meal group, the time taken for $\dot{\mathrm{V}}_{2}$ to return to resting levels was significantly greater than the time required for $f_{\mathrm{H}}$ to return to its resting value (Fig. 2; paired $t$-test, $t_{6}=$ 4.33, $P<0.01)$.

\section{Respiratory Exchange Ratio (RER)}

The RER varied considerably within and between individual penguins. Furthermore, the pattern of change varied between the small and large meal groups (Fig. 3). In the small meal group, RER started at approximately 0.66 and, in the first 30$40 \mathrm{~min}$, declined to around 0.63 before increasing steadily to approximately 0.75 after $120 \mathrm{~min}$, a level that was maintained until the mean duration of digestion (185 min; Table 1). In the large meal group, RER started at approximately 0.69 before declining to 0.65 and then rising again to approximately 0.69 0.70 after $90 \mathrm{~min}$. Only after approximately $300 \mathrm{~min}$ did RER decline again toward 0.60 as the mean duration of digestion was approached (380 min; Table 1).

\section{Discussion}

Controls

In order to account for the possible effects of stress during hand-feeding of the penguins, control trials were conducted in which penguins were handled in the same way and the energetic cost of the recovery from this handling was subtracted during the subsequent calculations of SDA and DHB. Sham-fed Adélie penguin chicks showed the same response to handling as that shown during this study, and it took $59 \pm 21 \mathrm{~min}$ for their $\dot{\mathrm{V}}_{2}$ to return to resting levels (Janes and Chappell 1995). This is reported to represent $2.8 \% \pm 1.4 \%$ of the SDA in the chicks, though the meal size for this calculation is not specified. As in this study, this handling cost was subtracted during subsequent calculations of SDA. In the little penguins fed the large meal in this study, the handling costs were equivalent to $5.5 \%$ of the SDA. In our experience (J. A. Green, unpublished data), penguin chicks appear to be less distressed than adult birds during handling by experimenters, and this may explain the higher handling cost in adult little penguins compared with that in Adélie penguin chicks. 

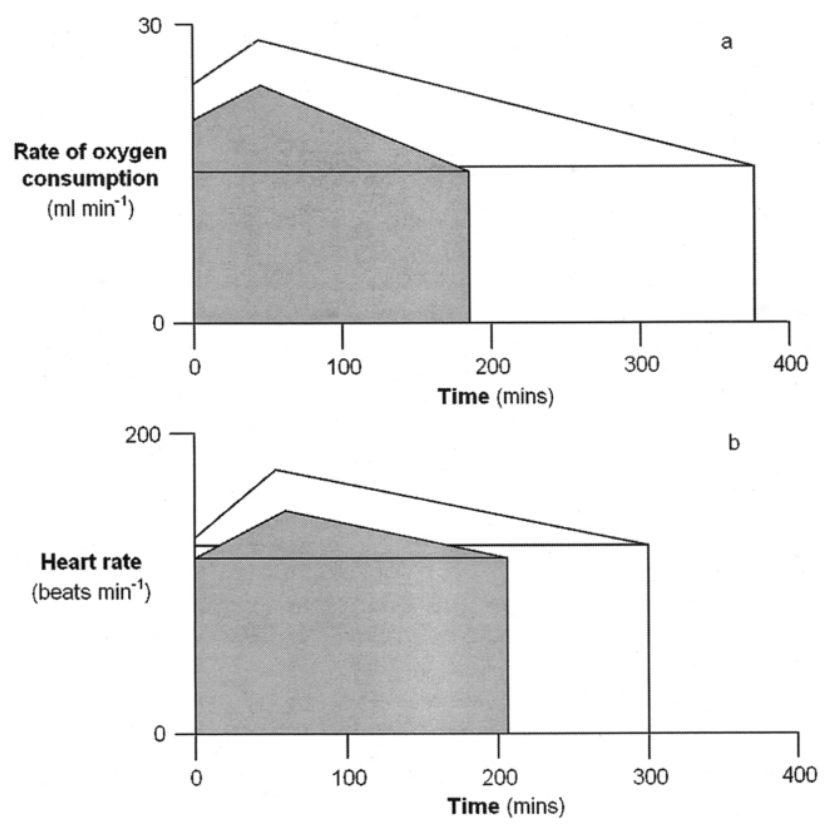

Figure 2. Schematic of the average responses of rate of oxygen consumption $\left(\dot{\mathrm{V}}_{2} ; a\right)$ and heart rate $\left(f_{\mathrm{H}} ; b\right)$ in little penguins while digesting either a small meal ( $n=6$; gray shaded shapes) of two sardines (mean mass $=30.5 \mathrm{~g})$ or a large meal $(n=6$; open shapes) of five sardines (mean mass $=74.9 \mathrm{~g}$ ). The rectangles show the amount of oxygen consumed and the number of heartbeats for resting or maintenance. The areas above the rectangles show the initial increase of $\dot{\mathrm{V}}_{2}$ and $f_{\mathrm{H}}$ above resting values and the subsequent steady decline back toward resting values. These areas are equivalent to the specific dynamic action and digesting heartbeats, respectively.

\section{Metabolic Costs of Eating Cold Food}

Only two previous studies have investigated SDA in penguins (Wilson and Culik 1991; Janes and Chappell 1995). Indeed, among all the seabirds, apart from a few measurements of postabsorptive MR (Baudinette et al. 1986; Croll and McLaren 1993), this vital component of energy budgets has been evaluated in detail only in Adélie penguins and Brünnich's guillemots (Uria lomvia; Hawkins et al. 1997). In their study, Wilson and Culik (1991) concluded that Adélie penguins do not show SDA while digesting a meal of krill and that observed increases in $\dot{\mathrm{V}}_{2}$ after digesting could all be attributed to the costs of warming their food to body temperature $\left(38.8^{\circ} \mathrm{C}\right)$ from that of the Antarctic Ocean $\left(0^{\circ} \mathrm{C}\right)$. In contrast, Janes and Chappell (1995) concluded that Adélie penguin chicks fed warm (body temperature) food did show SDA, equivalent to approximately $10 \%$ of the ingested energy or approximately $15 \%$ of the metabolizable energy.

It is possible to estimate the energetic cost of heating the food in this study with knowledge of the constituents of the diet and application of simple thermodynamic principles. If the proportion of each constituent of the sardines is multiplied by the specific heat capacity of that component and these values are summed (see Table 3 ), then it is possible to derive a specific heat capacity for West Australian sardines of $3.40 \mathrm{~J} \mathrm{~g}^{-1}{ }^{\circ} \mathrm{C}^{-1}$. In this study, the mean mass of the sardines fed to the penguins was $15.05 \mathrm{~g}$. Since $\mathrm{SDA}_{\mathrm{m}}$ is independent of meal size, we can calculate costs for a single fish. The total energetic cost of heating a single sardine from $7^{\circ}$ to $38.4^{\circ} \mathrm{C}$, the body temperature of a little penguin (Stahel and Nicol 1982), would be $1.61 \mathrm{~kJ}$. The mean $\mathrm{SDA}_{\mathrm{m}}$ in this study was $33.0 \pm 3.6 \mathrm{~mL} \mathrm{O}_{2}(\mathrm{~g} \text { fish })^{-1}$, which can be converted to MR using the literature values for energy released by the constituent components of sardines (Table 3). The total SDA for a $15.05-\mathrm{g}$ fish would then be $9.30 \mathrm{~kJ}$. The total energy content of a 15.05-g sardine can also be estimated (Table 3). Little penguins digest sardines with an energy metabolizability of 0.75 (Frankel 1997), so the total energy available to the penguin would be $57.6 \mathrm{~kJ}$. The cost to the penguin of heating the sardine from $7^{\circ} \mathrm{C}$ to body temperature would therefore be $2.8 \%$ of the metabolizable energy of the sardine. Gross $\mathrm{SDA}$, including this cost $\left(\mathrm{SDA}_{\text {gross }}\right)$, would be $16.2 \%$ of the metabolizable energy of the sardine. The cost of heating the sardine would represent $17.3 \%$ of $\mathrm{SDA}_{\text {gross }}$.

Net SDA, excluding the cost of heating $\left(\mathrm{SDA}_{\text {net }}\right)$, for little penguins would therefore be $13.4 \%$ of the metabolizable energy of the sardine. Clearly, $\mathrm{SDA}_{\text {gross }}$ will vary with the temperature of the water and therefore the fish at the time of ingestion. Water temperature in the Bass Strait close to Phillip Island where the little penguins used in this experiment would forage ranged from $12.3^{\circ}$ to $20.1^{\circ} \mathrm{C}$ during 2005 (A. Watkins, personal communication). As a result, $\mathrm{SDA}_{\text {gross }}$ for the little penguins in this study ranged from $15.0 \%$ to $15.7 \%$ of the metabolizable energy content of the fish, but this value may be higher for little penguins living at more southerly latitudes (Williams 1995), where sea temperatures will be cooler.

\section{Comparison of Metabolic Costs with Other Studies}

$\mathrm{SDA}_{\text {net }}$ of $13.4 \%$ of metabolizable energy in this study is similar to the value of $14.8 \%$ found in Adélie penguin chicks fed warm food (Janes and Chappell 1995). As in this study, Janes and Chappell (1995) also found that $\mathrm{SDA}_{\mathrm{m}}$ was independent of meal size. Peak postprandial $\dot{\mathrm{V}}_{2}$ in the Adélie penguin chicks was between $25 \%$ and $154 \%$ greater than resting levels but was independent of meal size. In this study, peak $\dot{\mathrm{V}}_{2}$ increased with meal size. In the large meal group, peak $\dot{\mathrm{V}}_{2}$ was $87 \%$ greater than resting levels, which was the same as the $87 \%$ increase observed in little penguins fed a meal of $100 \mathrm{~g}$ of (nonspecified) fish (Baudinette et al. 1986). In this study, the timing of peak $\dot{\mathrm{V}}_{2}$ was independent of meal size, though this is partly dependent on the cessation of the elevation of $\dot{\mathrm{V}}_{2}$ associated with handling. Peak $\dot{\mathrm{V}}_{2}$ occurred after an average $( \pm S D)$ of $43 \pm 14 \mathrm{~min}$, which was sooner and less variable than the $73 \pm 22 \mathrm{~min}$ in the Adélie penguin chicks. However, the chicks were fed warm food, so they had no immediate costs associated 


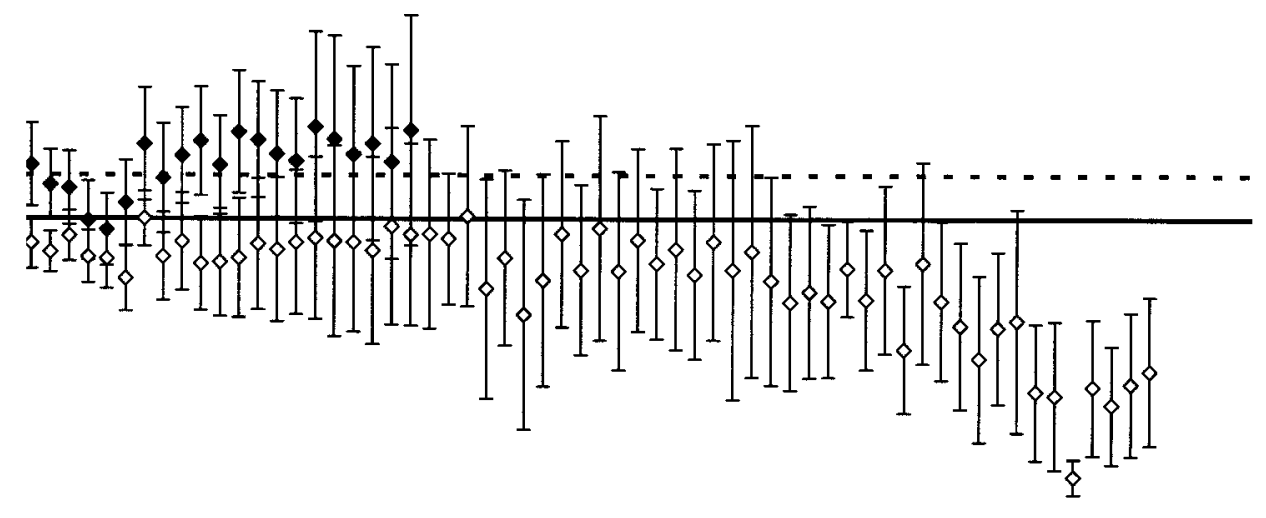

$\begin{array}{cccccc}100 & 150 & 200 & 250 & 300 & 350\end{array}$

Figure 3. Mean \pm SEM respiratory exchange ratio (RER; rate of carbon dioxide production/rate of oxygen consumption) measured while little penguins digested either a small meal $(n=6$; mean mass $=30.5 \mathrm{~g}$; solid symbols) or a large meal $(n=6$; mean mass $=74.9 \mathrm{~g}$; open symbols $)$. Also shown are the expected values of RER when birds metabolize pure lipid (solid line) or pure protein (dashed line; Schmidt-Nielsen 1997).

with heating food, and $\dot{\mathrm{V}}_{2}$ did not increase immediately after feeding. In adult Adélie penguins (which did not show $\mathrm{SDA}_{\text {net }}$ ) fed cold food or cold water, $\dot{\mathrm{V}}_{2}$ increased immediately and reached very high peaks (up to four times resting) in less than $10 \mathrm{~min}$ (Wilson and Culik 1991). The initial increase in $\dot{\mathrm{V}}_{2}$ and subsequent peak after $45 \mathrm{~min}$ in this study is consistent with the combined effects of both heating and digesting the meal. The lack of $\mathrm{SDA}_{\text {net }}$ in adult Adélie penguins is somewhat of a mystery, though it may be a result of the low protein content of krill. Alternatively, the food may have been heated through the reduction in thermolytic pathways elsewhere in the body and diversion of metabolic energy to the heating of food. It was not possible to measure such changes in circulation and blood flow in either Wilson and Culik's or this study, and it was assumed that they did occur, but this may be the subject of future work. In this study, duration of digestion increased with meal size, but since peak $\dot{\mathrm{V}}_{2}$ and the gradient of the decline from this point were greater for the large meal group, the increase in duration was not proportional to meal size (Table 1; Fig. 2). Janes and Chappell (1995) also found that duration of digestion increased with meal size, but again, not proportionately so.

There were also similarities and differences between the data from this study and SDA in Brünnich's guillemots feeding on Arctic cod (Boreogadus sadia; Hawkins et al. 1997). The guillemots fed voluntarily on cold $\left(0^{\circ} \mathrm{C}\right)$ fish that were approximately $2.3 \%$ of their own body mass, similar to the small meals ingested by penguins in this study $(2.8 \% \pm 0.16 \%$ of body mass). In the guillemots, $\dot{\mathrm{V}}_{2}$ increased initially by $40 \%$, similar to the $44 \%$ increase in this study. However, in contrast to the little penguins, $\dot{\mathrm{V}}_{\mathrm{O}_{2}}$ did not increase further but declined with a very shallow gradient for approximately $80 \mathrm{~min}$ before a sharp decline to resting levels. While this pattern of change differs from that observed in little penguins, $\mathrm{SDA}_{\text {net }}$ was similar at 9.4\% of the energy content of the fish. RER measured in the guillemots showed a slightly different pattern from that in the little penguins, increasing immediately from 0.71 , a level associated with fat metabolism, to around 0.74 , indicating metabolism of the protein in the ingested fish. In the little penguins digesting a small meal, RER also increased to 0.74 , but this increase occurred over a much longer period. At the beginning of digestion, RER of little penguins was relatively low at around 0.65 , which is lower than is normally expected for conventional metabolism. However, recent studies have shown that such low values of RER are not unusual in both absorptive and postabsorptive birds and indicate that more research is required in this area (Chaui-Berlinck and Bicudo 1995; Walsberg and Wolf 1995).

\section{Implications for Energy Budgets}

In recent years, several authors have speculated on the role of SDA in thermoregulation, specifically whether the excess heat generated as a result of SDA might be substituted for thermoregulatory costs when animals are at ambient temperatures below their thermoneutral zone. The picture in both birds and mammals is rather ambiguous, with some species showing complete or partial substitution (Costa and Kooyman 1984; Chappell et 
Table 3: Parameters relating to energy metabolism and digestion of sardines by little penguins

\begin{tabular}{|c|c|c|c|c|c|c|c|}
\hline & Protein & Lipid & Ash & Other & Water & $\begin{array}{l}\text { Total } \\
(\text { g sardine })^{-1}\end{array}$ & Source \\
\hline Wet mass $(\%)$ & 17.25 & 5.16 & 3.42 & 4.17 & 70 & 100 & Frankel and Smith 1998 \\
\hline Specific heat $\left(\mathrm{kJ}{ }^{\circ} \mathrm{C}^{-1} \mathrm{~g}^{-1}\right)$ & 1.05 & 2.51 & 0 & 4.17 & 4.17 & 3.40 & Kaseloo and Lovvorn 2003 \\
\hline Energy released by substrate $\left(\mathrm{kJ} \mathrm{g}^{-1}\right)$ & 17.8 & 39.3 & 0 & 0 & 0 & 5.10 & Schmidt-Nielsen 1997 \\
\hline $\begin{array}{l}\text { Energy released per unit of oxygen } \\
\quad\left(\mathrm{kJ}\left[\mathrm{L} \mathrm{O}_{2}\right]^{-1}\right)\end{array}$ & 18.4 & 19.7 & & & & 18.70 & Schmidt-Nielsen 1997 \\
\hline
\end{tabular}

al. 1997; Bech and Praesteng 2004) and others showing no substitution (Campbell et al. 2000; Kaseloo and Lovvorn 2003). Rosen and Trites (2003) also showed no thermal substitution by SDA in Steller sea lions (Eumetopias jubatus) and reviewed a number of studies in which substitution was present or absent. They concluded that more studies need to be performed, but with the data currently available, there are no clear taxonomic, ecological, dietary, or developmental explanations for whether different species show thermal substitution.

Clearly, further studies are required on the little penguin in order to establish whether SDA could substitute for thermoregulation. When in water at $20.1^{\circ} \mathrm{C}$, the warmest sea temperature likely to be encountered by little penguins from Phillip Island, their resting MR is $45 \%$ greater than that on land (Stahel and Nicol 1982). At $12.3^{\circ} \mathrm{C}$, the coolest sea temperature likely to be encountered, this increase rises to $69 \%$. If some of these costs could be substituted for by the excess heat produced during SDA (39\% increase above resting in $\dot{\mathrm{V}}_{2}$ during digestion in the present study; Table 1), then this could represent a substantial saving in their daily and annual energy budget. Little penguins at Phillip Island engage in foraging trips of varying durations yet only return ashore with an average stomach contents mass of $47 \mathrm{~g}$, or $4.2 \%$ of their body mass (Cullen et al. 1992). Food consumption rates are estimated to vary throughout the year from as little as $74 \pm 37 \mathrm{~g} \mathrm{~d}^{-1} \mathrm{~kg}^{-1}$, when the penguins are in negative energy balance following moult, to $664 \pm 87 \mathrm{~g} \mathrm{~d}^{-1} \mathrm{~kg}^{-1}$, when they are provisioning large chicks (Gales and Green 1990). This suggests that little penguins opt to digest most of their meals while at sea, which is also consistent with the rapid onset of SDA seen in this study. The penguins have to undertake many other metabolically costly activities while at sea (traveling, foraging, etc.). If SDA was an additive rather than substitutive cost, then this might limit the ability of the penguins to perform these other activities. The alternative strategy of digesting food while ashore would incur an SDA cost of approximately $2,442 \mathrm{~mL} \mathrm{O}_{2}$ for a meal size of $74 \mathrm{~g}$, rising to $21,912 \mathrm{~mL} \mathrm{O}_{2}$ for a meal size of $664 \mathrm{~g}$. If it is assumed that digestion was spread throughout the night and that during this time the penguins had a MR equivalent to the resting values obtained from this study, this would be equal to an increase in MR of $22 \%$ to $201 \%$ above resting levels for a nighttime duration of $12 \mathrm{~h}$. Clearly, the penguins would save a substantial amount of energy if this excess cost was used to substitute for thermoregulatory costs while at sea. This circumstantial evidence suggests then that thermal substitution may well occur in this species, but confirmation of this awaits further study.

\section{Changes in Heart Rate}

With the exception of studies of humans, to our knowledge, $f_{\mathrm{H}}$ has been measured at the same time as $\dot{\mathrm{V}}_{\mathrm{O}_{2}}$ during digestion in only one other study of an endotherm (McPhee et al. 2003). Some studies have been conducted on mammals during feeding, but this presents different physiological challenges from those during digestion (Houpt et al. 1983; Grant et al. 1997). Wilson and Culik (1991, p. 152) measured $f_{\mathrm{H}}$ during their study of Adélie penguins but made no further mention of these data other than to state that "heartbeat frequencies were closely correlated with metabolic rate in all cases." In this study, the increase and then steady decline in $f_{\mathrm{H}}$ matched those in $\dot{\mathrm{V}}_{2}$ (Fig. 1). The characteristics of this pattern also matched the decline in $\dot{\mathrm{V}}_{2}$ in most respects (Tables 1,2 ). The only exception to this was the relatively short duration of the response in $f_{\mathrm{H}}$ when the penguins digested the larger meal, though there was still no significant difference in the $\mathrm{DHB}_{\mathrm{m}}$ between the two meal sizes. Therefore, although $f_{\mathrm{H}}$ may have recovered to resting levels in $78 \%$ of the time that $\dot{\mathrm{V}}_{2}$ recovered, the total magnitude of the change in $f_{\mathrm{H}}$ matched that of the change in $\dot{\mathrm{V}}_{2}$. The difference in duration may simply have been due to the variability in the relationship between $f_{\mathrm{H}}$ and $\dot{\mathrm{V}}_{\mathrm{O}_{2}}$ during digestion (Green et al. 2006). Studies of humans have also shown a greater increase in postprandial $f_{\mathrm{H}}$ with increasing meal size (Waaler et al. 1991; Sidery and Macdonald 1994).

In this study, mean $\dot{\mathrm{VO}}_{2}$ during digestion of the large meal was $46 \%$ greater than $\dot{\mathrm{V}}_{2}$ while at rest (Table 1). Mean $f_{\mathrm{H}}$ during digestion of the same meal was $21 \%$ greater than while at rest (Table 2); therefore, the remainder of the increase in $\dot{\mathrm{V}}_{2}$ was due to a $20 \%$ increase in oxygen pulse (OP; volume of oxygen consumed per heartbeat). Under our experimental conditions, it was not possible for us to ascertain the extent to which this increase in OP was due to a change in cardiac stroke volume and/or oxygen extraction by the tissues. Studies of humans have reported varying contributions of stroke volume to 
increases in cardiac output associated with digestion, but all report an increase in $f_{\mathrm{H}}$ (Waaler et al. 1991; Muller et al. 1992; Sidery and Macdonald 1994). McPhee et al. (2003) detected little or no change in postprandial $f_{\mathrm{H}}$, while $\dot{\mathrm{V}}_{2}$ increased steadily in Steller sea lions. Therefore, in contrast to the results in this study and those from humans, they concluded that all of the increase in $\dot{\mathrm{V}}_{2}$ during digestion was due to an increase in OP. As the authors themselves note, this is an unual result because cardiovascular adjustments of this type are not commonly observed under conditions of increased oxygen demand, whether this is induced by digestion, exercise, or other causes. The result of these findings was a difference in the relationship between $f_{\mathrm{H}}$ and $\dot{\mathrm{V}}_{2}$ between digesting and fasting exercising Steller sea lions. In little penguins, while there was a difference in the relationship between $f_{\mathrm{H}}$ and $\dot{\mathrm{V}}_{2}$ while they were exercising or inactive, there was no difference in the relationship between digesting and inactive penguins (Green et al. 2006). This suggests that while OP varied between exercise and activity, there was no change in OP between digesting and inactive penguins.

\section{Conclusions}

Little penguins show a substantial physiological response to feeding. The response of $\dot{\mathrm{V}}_{2}$ and $f_{\mathrm{H}}$ over the time course of digestion is similar to that recorded in other endothermic species. However, as with other studies of SDA, the timing of these events and response to differing meal sizes is particular to this species. Little penguins have an $\mathrm{SDA}_{\text {net }}$ that is equivalent to $13.4 \%$ of the metabolizable energy of their food source, and they probably have to spend additional energy on top of this to heat their food to body temperature. $\mathrm{SDA}_{\text {gross }}$ then constitutes a substantial, yet obligatory, portion of the energy budget in little penguins, though they may use this to substitute for thermoregulatory costs while at sea. Thus, $\mathrm{SDA}_{\text {net }}$ is proportional to meal size, so there is no digestive constraint on the size of prey items chosen during feeding dives. Changes in $\dot{\mathrm{V}}_{2}$ during digestion are matched by changes in $f_{\mathrm{H}}$, and as such, $f_{\mathrm{H}}$ could be used as a predictor of $\dot{\mathrm{V}}_{2}$ and hence MR in free-ranging digesting penguins.

\section{Acknowledgments}

We would like to thank Tobie Cousipetcos and Eva Suric, who assisted in feeding the penguins, and the staff of Phillip Island Nature Park, who provided the penguins for this study, especially Marg Healy and Peter Dann. Sea surface temperature data were obtained with the assistance of Andrew Watkins from the University of Melbourne. The original source for these data was Commonwealth Scientific and Industrial Research Organization Marine and Atmospheric Research. P.J.B. and J.A.G. were supported by the Natural Environment Research Council during the period of this study, and P.J.B. is a La Trobe University visiting distinguished professor of the Adaptive and Evolutionary Respiratory Physiology Laboratory.

\section{Literature Cited}

Baudinette R.V., P. Gill, and M. O'Driscoll. 1986. Energetics of the little penguin Eudyptula minor: temperature regulation, the calorigenic effect of food, and moulting. Aust J Zool 34: 34-45.

Bech C. and K.E. Praesteng. 2004. Thermoregulatory use of the heat increment of feeding in the tawny owl (Strix aluco). J Therm Biol 29:649-654.

Blaxter K. 1989. Energy Metabolism in Animals and Man. Cambridge University Press, Cambridge.

Campbell K.L., I.W. McIntyre, and R.A. MacArthur. 2000. Postprandial heat production does not substitute for active thermogenesis in cold-challenged star-nosed moles (Condylura cristata). J Exp Biol 203:301-310.

Chappell M.A., G.C. Bachman, and K.A. Hammond. 1997. The heat increment of feeding in house wren chicks: magnitude, duration and substitution for thermostatic costs. J Comp Physiol B 167:313-318.

Chaui-Berlinck G.J. and J.E.P.W. Bicudo. 1995. Unusual metabolic shifts in fasting hummingbirds. Auk 122:774-778.

Chiaradia A., A. Costalunga, and K. Kerry. 2003. The diet of little penguins (Eudyptula minor) at Phillip Island, Victoria, in the absence of a major prey-pilchard (Sardinops sagax). Emu 103:43-48.

Costa D.P. and G.L. Kooyman. 1984. Contribution of specific dynamic action to heat balance and thermoregulation in the sea otter Enhydra lutris. Physiol Zool 57:199-203.

Croll D.A. and E. McLaren. 1993. Diving metabolism and thermoregulation in common and thick-billed murres. J Comp Physiol 163:160-166.

Cullen J.M., T.L. Montague, and C. Hull. 1992. Food of little penguins Eudyptula minor in Victoria: comparison of three localities between 1985 and 1988. Emu 91:318-341.

Dann P., F.I. Norman, J.M. Cullen, F.J. Neira, and A. Chiaradia. 2000. Mortality and breeding failure of little penguins, Eudyptula minor, in Victoria 1995-96, following a widespread mortality of pilchard, Sardinops sagax. Mar Freshwater Res 51:355-362.

Frankel T.L. 1997. Nutritional balance studies with pilchards and squid in little penguins, Eudyptula minor. Proc Comp Nutr Soc 56:321.

Frankel T.L. and P. Smith. 1998. Fish sausages prove to be unsuitable for determining minimum protein requirements of the little penguin (Eudyptula minor). Proc Comp Nutr Soc 1:59-62.

Frappell P.B., H.A. Blevin, and R.V. Baudinette. 1989. Understanding respirometry chambers: what goes in must come out. J Theor Biol 138:479-494. 
Frappell P.B., C. Lanthier, R.V. Baudinette, and J.P. Mortola. 1992. Metabolism and ventilation in acute hypoxia: a comparative analysis in a small mammalian species. Am J Physiol 262:R1040-R1046.

Gales R. and B. Green. 1990. The annual energetics cycle of little penguins Eudyptula minor. Ecology 71:2297-2312.

Gallivan G.J. and K. Ronald. 1981. Apparent specific dynamic action in the harp seal (Phoca groenlandica). Comp Biochem Physiol A 69:579-581.

Grant D.A., J.E. Fewell, A.M. Walker, and M.H. Wilkinson. 1997. Oxygen transport and utilization during feeding in the young lamb. J Physiol 503:195-202.

Green J.A., P.B. Frappell, T.D. Clark, and P.J. Butler. 2006. Predicting rate of oxygen consumption from heart rate while little penguins work, rest and play. Comp Biochem Physiol A (forthcoming).

Hawkins P.A.J., P.J. Butler, A.J. Woakes, and G.W. Gabrielsen. 1997. Heat increment of feeding in Brünnich's guillemot Uria lomvia. J Exp Biol 200:1757-1763.

Houpt K.A., B.A. Baldwin, T.R. Houpt, and F. Hills. 1983. Humoral and cardiovascular responses to feeding in pigs. Am J Physiol 244:R279-R284.

Janes D.N. and M.A. Chappell. 1995. The effect of ration size and body size on specific dynamic action in Adélie penguin chicks, Pygoscelis adeliae. Physiol Zool 68:1029-1044.

Jensen P.G., P.J. Pekins, and J.B. Holter. 1999. Compensatory effect of the heat increment of feeding on thermoregulation costs of white-tailed deer fawns in winter. Can J Zool 77: 1474-1485.

Kaseloo P.A. and J.R. Lovvorn. 2003. Heat increment of feeding and thermal substitution in mallard ducks feeding voluntarily on grain. J Comp Physiol B 173:207-213.

MacArthur R.A. and K.L. Campbell. 1994. Heat increment of feeding and its thermoregulatory benefit in the muskrat (Ondatra zibethicus). J Comp Physiol B 164:141-146.

Markussen N.H., M. Ryg, and N.A. Øritsland. 1994. The effect of feeding on the metabolic rate in harbour seals (Phoca vitulina). J Comp Physiol B 164:89-93.
McPhee J.M., D.A.S. Rosen, R.D. Andrews, and A.W. Trites. 2003. Predicting metabolic rate from heart rate in juvenile Steller sea lions Eumetopias jubatus. J Exp Biol 206:19411951.

Muller A.F., L. Fullwood, M. Hawkins, and A.J. Cowley. 1992. The integrated response of the cardiovascular system to food. Digestion 52:184-193.

Rosen D.A.S. and A.W. Trites. 2003. No evidence for bioenergetic interaction between digestion and thermoregulation in Steller sea lions Eumetopias jubatus. Physiol Biochem Zool 76:899-906.

Rubner M. 1902. Die Gesetze des Energieverbrauchs bei der Ernahrung. Dauticke, Leipzig.

Schieltz P.C. and M.E. Murphy. 1997. Heat increment of feeding in adult white-crowned sparrows. Comp Biochem Physiol 118A:734-743.

Schmidt-Nielsen K. 1997. Animal Physiology. Cambridge University Press, Cambridge.

Sidery M.B. and I.A. Macdonald. 1994. The effect of meal size on the cardiovascular responses to food ingestion. Br J Nutr 71:835-848.

Stahel C.D. and S.C. Nicol. 1982. Temperature regulation in the little penguin, Eudyptyla minor, in air or water. J Comp Physiol 148:93-100.

Waaler B.A., M. Eriksen, and K. Toska. 1991. The effect of meal size on postprandial increase in cardiac output. Acta Physiol Scand 142:33-39.

Walsberg G.E. and B.O. Wolf. 1995. Variation in the respiratory quotient of birds and implications for indirect calorimetry using measurements of carbon dioxide production. J Exp Biol 198:213-219.

Williams T.D. 1995. The Penguins. Oxford University Press, Oxford.

Wilson R.P. and B.M. Culik. 1991. The cost of a hot meal: facultative specific dynamic action may insure temperature homeostasis in post-ingestive endotherms. Comp Biochem Physiol 100:151-154. 